\title{
Changes in RNA in the occipital cortex of rats as a function of light and dark during rearing'
}

\author{
RICHARD C. DEBOLD, WILLIAM FIRSHEIM, SAMUEL C. CARRIER, III ${ }^{2}$ AND RUSSELL. C. LEAF ${ }^{3}$
}

WESLEYAN UNIVERSITY

Hooded rats reared in darkness and then introduced to light showed selectively changed amounts of heavy molecular weight occipital cerebral cortex RNA, without similar changes in frontal cortex. Rats maintained in light, or dark, or changed from light to dark did not show similar effects.

Several recent findings and speculations have suggested that RNA may be involved in the encoding of experience in the brain. To explore this hypothesis, we manipulated opportunities for visual experience and analyzed the effects on the RNA in the cerebral cortex of rats.

Subjects

Ninety-nine hooded rats served as Ss for three experiments, as shown in Table 1.

\section{Apparatus}

Two identical ventilated light-tight steel cabinets served as rearing enclosures. Cages were placed on the shelves of each cabinet. A bright fluorescent tube illuminated each shelf of the Light Environment (L) cabinet, while shelves of the Dark Environment (D) cabinet were unilluminated.

\section{Experimental Designs}

In three similar experiments, Ss lived under four sets of illumination rearing conditions, as shown in Table 1.

In each experiment, the pregnant mothers were placed in the cabinets for the last two days of gestation. The pups were all cross-fostered within conditions and litters were equalized at five Ss after birth. The Ss were weaned at 21 days, and recaged three Ss per cage. At the times shown in Table 1 , half the $\mathrm{L}$ Ss were moved to the $\mathrm{D}$ environment, and half the D Ss to the L. Each experiment included rearing groups with L-L, L-D, D-L, and D-D histories. In Experiment 2, a group of diurnal-cycled Ss that lived in the breeding colony was also studied.

\section{Procedure}

The Ss were sacrificed by decapitation; cortical tissues were dissected as quickly as possible by blunt dissection of a single slab, wiped free of blood, and frozen on solid $\mathrm{CO}_{2}$. The occipital cortex, taken as the full bilateral width of the posterior half of the cortex (about $175 \mathrm{mg}$ ) was used in all experiments. The remainder of the cortical tissue (frontal cortex) and $1 \mathrm{gm}$ slices of liver tissue from each $S$ were also taken in Experiment 3.

In Experiment 1, total RNA/unit tissue weight was extracted and assayed separately for each $S$ by a hot tricholoacetic acid technique (Schneider, 1957).
In Experiments 2 and 3 a more sophisticated analysis was undertaken. Exactly $2.5 \mathrm{hr}$. before sacrifice each $S$ was injected intramuscularly with $20 \mu \mathrm{c}$ of $\mathrm{C}^{14}$-uridine, in order to detect rapidly labelled RNA (Hiatt, 1962). All the samples from each rearing condition were pooled. Isolation of total RNA from the frozen tissues was begun within .5 hr. after sacrifice by the method of Kidsen et al (1963), which effectively inhibits ribonuclease activity. For each analysis, a $1.5 \mathrm{mg}$ RNA sample in $50 \mathrm{ml}$ of potassium phosphate buffer (0.05 $\mathrm{M} \mathrm{pH} 6.7$ ) was adsorbed to an esterified bovine serum albumin column (Mandell \& Hershey, 1960). Elution of RNA was carried out by salt gradient from 0.3-2.1 $\mathrm{M} \mathrm{NaCl}$, in the phosphate buffer. Ultraviolet density of the eluate was monitored at $260 \mathrm{~m} \mu$ and $14 \mathrm{ml}$ fractions were collected, evaporated to $8 \mathrm{ml}$, and extracted into an organic solvent consisting of n-butyl alcohol, diethyldihexylamine, and glacial acetic acid $(100: 11.4: 2)$. The radioactivity of the top layer was counted.

\section{Resulits}

In Experiment 1, there were no significant differences in RNA/unit tissue weight among the four groups $(F<1)$. The fractionation procedures used in Experiments 2 and 3 were adopted because of this negative finding.

In Experiment 2, two striking differences between the D-L group and the other groups were apparent in the relative amounts of RNA contained in the highest

Table 1. The Designs of the 3 Experiments

\begin{tabular}{|c|c|c|c|c|c|}
\hline & Group & $N($ rats $)$ & $\begin{array}{l}\text { Days } \\
\text { Environment } 1\end{array}$ & $\begin{array}{l}\text { Days } \\
\text { Environmen }+2\end{array}$ & $\begin{array}{c}\text { Age at } \\
\text { Sacrifice }\end{array}$ \\
\hline & $L \cdot L$ & 14 & 51 & 7 & 58 \\
\hline \multirow[t]{5}{*}{ Exp. 1} & L-D & 11 & 51 & 7 & 58 \\
\hline & D-D & 12 & 51 & 7 & 58 \\
\hline & D-L & 10 & 51 & 7 & 58 \\
\hline & & 47 & & \multicolumn{2}{|c|}{ Average Age 58} \\
\hline & $L-L$ & 6 & 96 & 22 & 118 \\
\hline \multirow[t]{7}{*}{ Exp. 2} & L-D & 6 & 96 & 41 & 137 \\
\hline & $D \cdot D$ & 5 & 96 & 35 & 131 \\
\hline & D.L & 5 & 96 & 25 & 121 \\
\hline & Diumal- & & & & \\
\hline & Cycled & 6 & 142 & - & 142 \\
\hline & & 28 & & \multicolumn{2}{|c|}{ Average Age 130} \\
\hline & L-L & 6 & 80 & 63 & 143 \\
\hline \multirow[t]{4}{*}{ Exp. 3} & L-D & 6 & 80 & 43 & 123 \\
\hline & $\bar{D}-\bar{D}$ & 6 & 80 & 50 & 130 \\
\hline & D-L & 6 & 80 & 34 & 114 \\
\hline & & 24 & & \multicolumn{2}{|c|}{ Average Age 128} \\
\hline
\end{tabular}


Table 2. Relative Proportion of Various Optical Density Fractions in the Total Optical Density Profiles in Experiments 2 and $3^{*}$

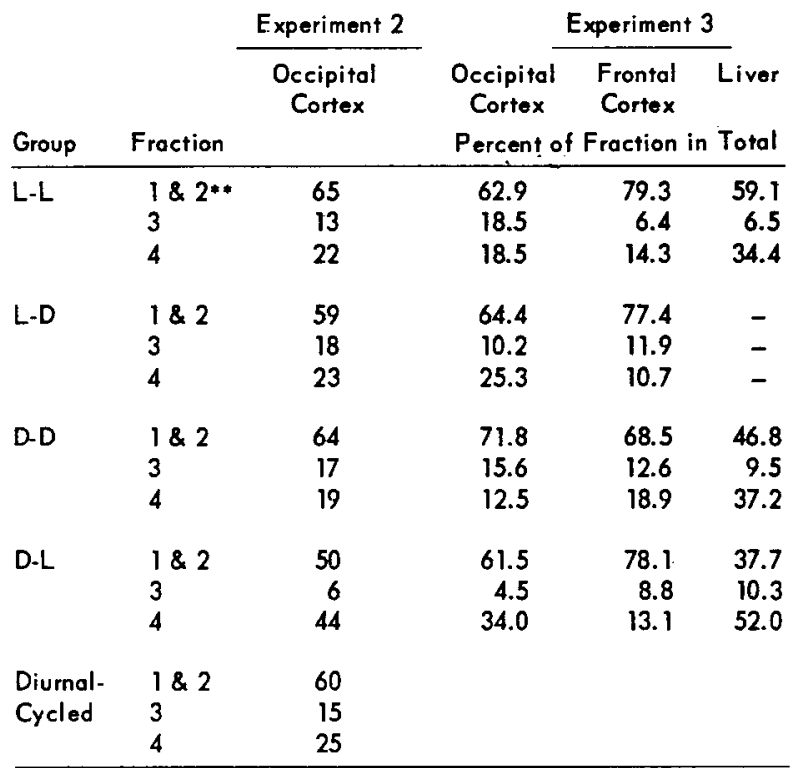

*All measurements were made by planimetric integration of the areas under the peaks.

* Fractions 1 and 2 were never completely separated, as noted above, and they were therefore measured together.

molecular weight fractions obtained. Optical density profiles yielded four fractions from each analysis, as separable or partially separable peaks. These consisted of a non-adsorbing fraction at $0.3 \mathrm{M} \mathrm{NaCl}$ (Fraction 1) which presumably contained transfer RNA (Philipson, 1960); a fraction which was only partially separated from Fraction 1 with a peak at $0.63 \mathrm{M}$ (Fraction 2) and was partially DNA (as judged by a positive diphenylamine reaction) together with a small amount of RNA (as judged by a low orcinol reaction); a high molecular weight RNA fraction with a peak at $0.9 \mathrm{M}$ (Fraction 3); and a final high molecular weight RNA fraction with a peak at 1.4 M (Fraction 4). As shown in Table 2, the percent of the sample found in Fraction 4 was markedly elevated in the D-L Ss, and the percent of the sample found in Fraction 3 was markedly reduced.

These findings were confirmed in Experiment 3, as shown in Table 2. In Experiment 3 a different pattern of confounding of age at sacrifice with time in Environment 2 was used than in Experiment 2 in order to partially separate the effects of age from those of the rearing treatments. The obtained replication of shifts in percentage of RNA in the high molecular weight fraction is, thus, likely to be due to the rearing conditions rather than to the age variable. In addition, Experiment 3 indicated that the obtained shifts are likely to be statistically reliable. Using the treatment groups as the unit, the D-L group had a $1 / 5$ chance of being most extreme in its value for Fractions 3 and 4 in Experiment 2 and $a 1 / 4$ chance of being similarly extreme in Experiment 3. The combined probability of these independent results is $p=1 / 20$, or .05 for each of the two changes.

The results of Experiment 3 also suggested that the shifts were specific to the occipital cortex. No similar differences between the D-L and other groups were found in samples from frontal cortex.

The analyses of radioactivity in rapidly labelled RNA from Experiments 2 and 3 provided much less systematic findings than the optical density measurements, even though a great deal of the rapidly labeled material was in Fractions 3 and 4. The radiometric results will therefore not be described.

\section{Discussion}

Only tentative conclusions can be drawn from these preliminary findings, in view of the exploratory character of our studies. We are, nevertheless, impressed with consistent evidence indicating that metabolic changes occurred within the occipital cortex of darkreared rats introduced to light in adulthood. The observed changes were subtle, for there were no differences in total RNA in the occipital cortex. While subtle, these effects of visual experience seem specific to occipital cortex.

The differences between D-L Ss and the others may have been due to changes in the rates of synthesis, the rates of breakdown, or both, of the high molecular weight RNAs. It is essential to devise procedures for independently assessing these rates of synthesis and turnover. Speculation about the biochemical mechanisms underlying the changes in the D-L Ss must await clarification from such studies.

The observed changes may have reflected relatively permanent alterations of function. These alterations might be reflections of specific demands for growth in a particular, previously hypoactive, cortical region in the D-L Ss; or they might be physiological concomitants of a process of "learning to see." In either case, they may be associated with the record of experience in the brain.

\section{References}

Hiatt, H. H. A rapidly labeled RNA in rat liver. J. Mol. Biol., $1962,5,217-229$.

Kidson, C., Kirby, K. S., \& Ralph, R. K. Isolation characteristics of rapidly labelled RNA from normai rat liver. J. Mol. Biol., $1963,7,312-315$.

Mandell, J. D., \& Hershey, A. D. A fractionating column for analysis of nucleic acids. Analytical Biochemistry, 1960, 1, 66-77. Philipson, L. Chromatographic separation, and characteristics of nucleic acids from HeLa cells. J. gen. Physiol., 1960, 44, 899910.

Schneider, $\boldsymbol{W}$. C. Determination of nucleic acids in tissues by pentose analysis. In S. P. Colowick \& N. O. Kaplan (Eds.), Methods in enzymology. New York: Academic Press, 1957.

\section{Notes}

1. This research was partly supported by NIH Grant 12299-01, and by NSF Grant GB-5949 to the senior author.

2. Now at University of California, Berkeley.

3. Technical help of S. Novick and M. Lappe is appreciated. 